\title{
Merging Culture into Foreign Language Teaching
}

\author{
Shuguang Zhang \\ School of Foreign Languages, Chifeng University, Chifeng, Inner Mongolia, China \\ 05012311@163.com
}

Keywords: Culture; Language; Teaching; English

\begin{abstract}
Culture is an indispensable part of foreign language teaching. Accordingly, this paper tries to strike the point that English teachers in China should teach English culture in their class. First, it states out the present situation of cultural teaching and learning. Second, it emphasizes the necessity of teaching about English culture. English teaching is seen as a process of infusing both the target language and the target culture, which is interwoven into language itself. Last, it discusses what types of culture the English teachers in china should teach about, intending to provide the Chinese language educators with certain guidance and inspiration to more effective culture teaching methods.
\end{abstract}

\section{Present Situation of Cultural Teaching and Learning}

The teaching of culture in English class is a simple yet very complex issue that has been debated for over a century. Foreign language teaching makes a small contribution to the general education if it is only taught in its narrow linguistic notion.

English has been taught as a foreign language in the schools of China for a very long time. Both the teachers and students have spared no efforts to teach and learn it. Many of them do have made great achievement. However, due to various reasons, the average level of English is far from satisfaction, especially when it comes to the communicative competence which is treated as the core of English teaching and learning. Among all the reasons, the lack of cultural education is by no means a minor one [1].

Traditionally, though there were many methods, English was mainly taught in the way of grammar translation which got the learners to translate English into Chinese or vise versa. In the teaching of English little attention was paid to the cultivation of communicative competence, which is essentially determined by the nature of any language. What's more, English textbooks were mostly compiled by Chinese people instead of native speakers. Therefore, the language taught and learned was not the genuine one. What's more, there was little exposure to the culture of the English-speaking countries.

In recent years, fortunately, more stresses have been laid on the improvement of communicative competence. Many functional approaches have been adopted in English teaching and learning in most schools. But since both the teaching and learning focus themselves on tests, the importance of cultural education is still kept in low profile. How to pass various kinds of tests becomes most teachers and students' great concern. Lots of time and energy in or after class are spent in achieving high marks in exams of all kinds, leaving little room for cultural activities. In this sense, although basic skills of listening, speaking, reading, writing and translating have been much improved, cultural deficiencies are still apparently felt [2].

On some occasions in cross-cultural communication, just because of cultural differences, even if we speak a foreign language grammatically correct, we cannot communicate tactfully and appropriately. Students cannot make effective conversation, thus leading to the failure in the communication. So teaching about English should not only include the forms of the target language itself but also its culture. English teachers in China have the responsibility to help students learn about English culture in their class. 


\section{Necessity of Teaching about English culture}

Relations between Culture and Language. Language and culture are not two independent items. Actually, they are closely related with each other. Culture and language are inseparable and constitute a single universe or domain of experience [3]. Language and culture are so intricately intertwined that sometimes the connections between the two are taken for granted as self-evident. Language is at different levels being connected to culture. On the one hand, every language is part of culture. Culture consists of customs, habits, way of behavior, sense of value, sense of beauty, and language. On the other hand, language is the carrier of culture, i.e., language is primary means by which culture transmits its beliefs, values and norms. As has been repeatedly testified, culture is always reflected in language and there is no separation between understanding language and understanding culture. You can see the national culture from its language. In fact, Learning English vocabulary is learning western culture.

Language is affected by the culture, and reflecting culture [4]. We can say that language reflects a national characteristic, for a specific language not only contains the national historical and cultural background, but also reveals its life style and way of thinking. A language's lexicon and syntax could both reflect its users' cultural values. Oppositely, cultural patterns also exist itself in human communicative behavior. It seems that only when language is being linked to the specific community's cultural reality does it being known as much more than a simple communication tool. Every language reflects the values, beliefs and assumptions of the culture it comes from, which means learning a language has to be involved with the learning of the culture which the language expresses.

Culture and Foreign Language Learning. Listening is one essential step to master English, and also students' weak point. In order to improve competence of listening comprehension, some students specially buy tape recorders for listening and spend quite a few hours on it every day. However, they fail to understand again once they meet new materials. The reasons lie in two aspects. On the one hand, maybe some students' English is very poor and they have not grasped enough vocabularies, clear grammar, correct pronunciation, or maybe the material is rather difficult. On the other hand, an important reason is that they are unfamiliar with cultural background of English-speaking countries. Aural comprehension, which is closely related to the knowledge of culture, in fact, examines one's comprehensive competence which includes one's English level, range of knowledge, competence of analysis and imaginative power [5].

Many students may have this kind of experience: when they are listening to something familiar to them, no matter what is concerned, it is usually easy for them to understand. Even if there are some new words in the material, they are able to guess their meanings according to its context. However, when they encounter some unfamiliar material or something closely related to cultural background, they may feel rather difficult. Even if the material is easy, they only know the literal meaning, but cannot understand its connotation. Here is a sentence from a report: "The path to November is uphill at all way." "November" literally means "the eleventh month of year". But here refers to "The presidential election to be held in November". Another example is "red-letter days" which is a simple phrase, meaning holidays such as Christmas and other special days. Yet, students are often unable to understand them without teachers' explanation. In view of this, the introduction of cultural background is necessary in the teaching of English listening.

Likewise listening, speaking is not merely concerned with pronunciation and intonation. Students can only improve their oral English and reach the aim of communication by means of enormous reading, mastering rich language material and acquaintance of western culture. Therefore, in oral training, teachers should lay stress on factuality of language and adopt some material approaching to daily life. When the material is from real life, it helps students to be well acquainted with standard pronunciation and intonation, to speak English appropriate to the occasion, to understand western life and customs. Otherwise, it would unavoidably lead to misunderstanding and unhappy. Many fixed English expression cannot be changed randomly. During oral communication, speakers need standard pronunciation and intonation, as well as the suitable use of language for the occasion. 
Reading English articles requires a certain language basis, but the competence of reading comprehension is not only related to one's language level. Knowledge of cultural background is also important. Reading competence is affected by one's language knowledge, cultural background knowledge and other professional knowledge [6]. When students read English articles, cultural differences between Chinese and western people often bring them many difficulties. For example, some common terms or expressions in English reading material are often not understood by Chinese learners unfamiliar with English-speaking culture. Many allusions drawn from history, religious, and literature, often appear in English works and have become common household terms. But without the knowledge of western culture and history, it is not easy for Chinese to understand those allusions. Without understanding there could be little appreciation.

Translation cannot be conducted at a purely linguistic level but must incorporate cultural and contextual factors, too [7]. To a large degree, translation is related to culture, influenced and restricted by culture. For instance, one best-known type of batteries in China is called bai xiang in Chinese and has been sold well domestically. Yet, it is quite unsalable on international market. The reason lies in its English translation - White Elephant, which in English culture refers to something useless and burdensome rather than an elephant with the color of white. If the translator had known the cultural differences better, this kind of failure would not have happened.

Other Factors Calling for Culture Teaching. Besides those mentioned above, there are also some other factors which call for the teaching about English culture. First, with the development of globalization and digitalization, a healthier pedagogical philosophy should be developed in the field of language teaching so that sufficient attention could be paid to sociological and culture studies. For this reason, it has become urgent and indispensable responsibility for teachers to make the students familiar with cultural differences.

Second, as Hu and Gao [8] rightly points out, the learner's motivation could be greatly enhanced by virtue of the input of cultural things in a given language. A satisfactory mastery of a foreign language can never be achieved if we ignore the factors such as motivation and empathy in language learning.

Third, as a part of liberal education, the effort to teach about culture will provide the students enough information to transcend their own culture and develop a more objective consciousness of the related issues about English-speaking countries.

\section{Contents of Culture Teaching in Language Classroom}

A successful master of a given language has much to do with an understanding of its culture, because language and culture are correlated with each other at different level of linguistic structure. Since cultural enhancement is so important in the process of language learning, I will take a more classroom-based perspective and examine the issue of what to be given in the classroom. Practically, there are three types of culture available for our language classroom. They are anthropological culture, history of civilization culture, and mini-culture such as "pop culture, travel culture, scientific culture" [9] or the culture embedded in the concept of "WORLD ENGLISHES".

The content of the first type of culture involves some fundamental features concerning the development of cultural competence in language learning. It emphasizes the inclusion of a complex package of things such as belief, knowledge, attitude, values, behavior, and thinking patterns in a given culture. The message concerning geographical features, historical developments, and achievements of civilization and science of a certain culture are some necessary focuses for the teaching of the second type of culture. The last type of culture indicates a rather loose definition to the scope, which reflects a prolific source of materials that could be used to enhance learners' consciousness of the concept of "the international English" or the diversity of subculture in world English. Having specified the general scope of what to be taught in a language classroom, some cautions should be taken in how to render the cultural stuff in practice. 


\section{Conclusion}

As is explained above, language is inseparably integrated with culture, so it is necessary to teach about English culture in English class learning [10]. The more knowledge students have about the English culture, the more it will promote their English learning. Thus, the English teachers should adopt various ways to teach culture knowledge and make the students aware of cultural differences between China and English-speaking countries. In doing so, students' English proficiency and communicative competence will surly be improved.

\section{References}

[1] Shotton, R: Language Learning Journal, Vol. 21 (1991) No.3, p. 68-70

[2] Grice, H. P: Logic and conversation. In Cole, P., and Morgan, J., editors, Syntax and Semantics 3: Speech Acts, (Academic Press, America, 1975), p. 41-58.

[3] Kramsch, C: Context and Culture in Language Teaching (Oxford University Press, England 1993).

[4] Steele, R: Teaching language and culture: Old problems and new approaches. In J.E. Alatis (Eds.), Georgetown University roundtable on languages and linguistics (Georgetown University Press, America 1989).

[5] Valdes, J: Culture bound: Bridging the culture in language teaching (Cambridge University Press, Britain 1986).

[6] Scott, V. M and J. A. Huntington: Foreign Language Annals, Vol. 35 (2000) No.6, p. 622-631.

[7] Whorf, L: Language, Thought, and Reality (MIT Press, Britain 1956).

[8] Alptekin, C: The Target - language Culture in EFL Materials (Oxford University Press, England 1993).

[9] Valdes, J: The Inevitability of Teaching and Learning Culture in a Foreign Language Course. In Harrison B. (Eds.), Culture and the Language Classroom (Modern English Publications, HongKong China 1990). 